\title{
Casa de las Ideas
}

MARCEL SANCHEZ-PRIETO

Woodbury University

The digital library Casa de las Ideas is located along a canal that runs through the Colonia Camino Verde in Tijuana, Mexico. Adjacent buildings, mostly homes and businesses built informally, face the channel, where a large public activity, transportation and both formal and informal businesses are concentrated. Two challenges characterize this area: crime and flooding. The library is part of the urban development plan, an initiative by SEDESOL (Ministry of Social Development), which provides not only the channeling of the river, but the integration of a series of public spaces, parks, recreational areas, community center and a library along the river. The aim is to improve the quality of life of its residents and combat crime through the design of civic spaces, infrastructure and cultural programs.

Casa de las Ideas is a 220 square meter digital library. The small space parameters and the questioning on what a digital library should be, gave an opportunity to propose a new type of library: a collective space where learning and research steps beyond information services. Sequencing interior and exterior stages, the form of the library host an interior theatre for studies, conferences and workshops; the slope created by the different platform levels articulates a void in the exterior, becoming a backstage for cultural events and public gatherings. The sequential spatial cascade of scenarios transforms the massing of the building into a fully porous space accessible to the public, even outside of the library's hours of operation. The library turns over the

\section{ADRIANA CUELLAR}

University of San Diego

challenges of the park by breaking alienation of building into opportunities for spatial negotiations, incentivizing civic life to its adjacent social and urban context. 

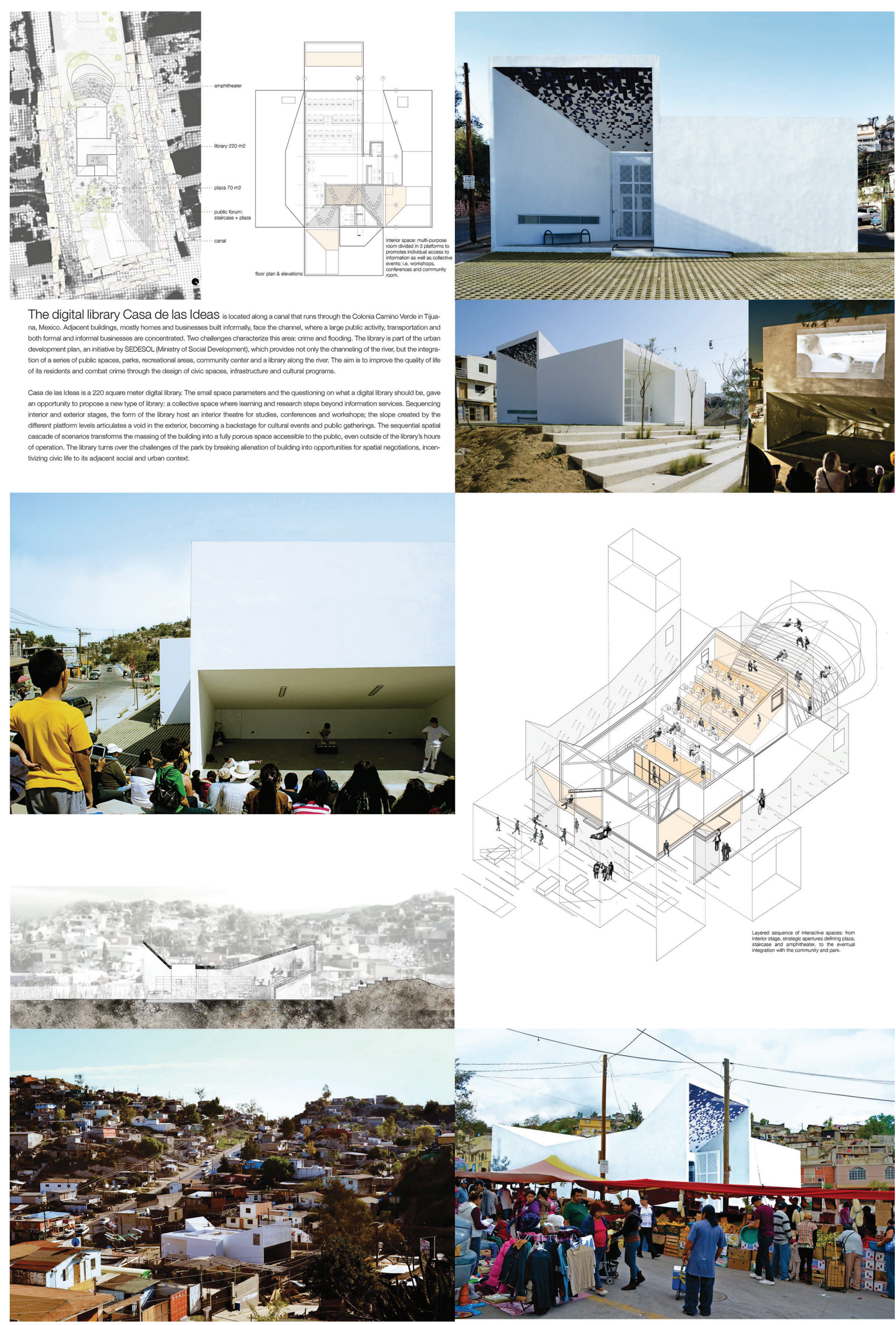